\title{
Exploring the Stumbling Blocks Lying along the Government-NGO Cooperation in the HIVIAIDS Domain Service Delivery: The Case of Institute of Youth Development South Africa (IYDSA) in East London, Eastern Cape Province
}

\author{
Prof. S. M Kang'ethe \\ University of Fort Hare, Department of Social Work and Social Development \\ Box X1314, Alice, 5700, South Africa \\ Email: skangethe@ufh.ac.za \\ Mr. Tatenda Manomano \\ PhD in Social Work Student, University of Fort Hare \\ Box X1314, Alice, 5700, South Africa \\ Email: 200706055@ufh.ac.za
}

Doi:10.5901/mjss.2014.v5n23p1858

\section{Abstract}

An array of empirical researches corroborated with observation on the ground seem to suggest that collaboration between the government and NGOs could be a panacea that could foster efficient and effective service delivery to the citizens of a particular country. This study sought to explore the panacea of collaboration between Government and NGOs in service delivery. This study adopted a qualitative research methodology to explore the perceptions, views, thoughts and opinions of the participants. The design took the form of a case study. The study utilized an interview schedule with semi structured questions as a data collection tool. Focus group discussion method was used as a data collection method to collect data from 9 nurses from Institute of Youth Development South Africa (IYDSA) who would go and train nurses in Primary health care facilities of the government because the researcher wanted information that could capture the collaboration relationship between IYDSA and the government. The researchers utilized an in-depth interview to collect data from the Monitoring and Evaluation manager as well as the Pharmacist as these two acted as key informants for the study. The findings revealed that there were financial challenges in government hospitals, poor infrastructure in government hospital facilities, shortage of human resources such as data capturers and nurses; lack of progress in the meetings as well as bad roads and long distances leading to the these rural primary health care facilities among other things. The government has been recommended to create an enabling environment for collaboration between the NGOs and primary health care facilities in service delivery; proper funding of government hospitals as well as recruitment of adequate staff; improvement of roads and other hospital infrastructure to enhance the ARV treatment among other things.

Keywords: People Living with HIVIAIDS (PLWHA), Nurse Initiated and Management of Anti-retroviral Treatment (NIMART), nurses.

\section{Study Aims and Objectives}

While the broad aim and objective from which this article has been derived sought to explore the challenges faced by beneficiaries in implementing ARV treatment through Nurse Initiated and Management of Anti-retroviral Treatment (NIMART) in the Eastern Cape Province, this article aims to explore the panacea of collaboration between NGOs and the government in service delivery.

\section{Problem Statement}

The South African government among other countries has made significant strides in combating the impact of HIVIAIDS among its people with NGOs increasingly supplementing and complementing the effort to strengthen the fight. However, despite the collaboration and cooperation between the two players has always been viewed as a panacea or very desirable, these researchers doubt the role of the government in strengthening the pact among some NGOs programmes pursuing administration and dispensing of ARV to the needy communities. These researchers consider that it is government's role to see to it that the task of ARV administration and dispensing of medication is expeditiously handled. It is also expected that with the collaboration and cooperation of the NGOs especially pursuing the same goal, the 
government would consider it a panacea and therefore fully support these NGOs. Unfortunately, these researchers cast doubt of the commitment of the government in collaborating and cooperating with some of these NGOs. Therefore, these researchers intend to evaluate the government role in fostering the government-NGO collaboration and cooperation in the field of HIVIAIDS through investigating the NIMART (Nurse Initiated in the Management of Anti-Retroviral Therapy) programme run by IYDSA programme Institute of Youth Development South Africa (IYDSA) in East London, Eastern cape Province. Such an investigation, these researchers hope could help unearth the underpinning factors behind such kind of unexpected weird attitude from the same government which should be extending its hand to reach out to the NGOS because of the role they play in filling gaps that the government may not always be able to fill. Such an investigation is likely to keep the government on its toes towards reinforcing the fight against the impact of HIVIAIDS.

\section{Introduction and Background}

HIVIAIDS has attracted global attention given that it has claimed millions and millions of lives unabatedly (Barnett \& Whiteside 2006; Ramphele 2008). Scaringly and unfortunately, HIVIAIDS has resulted in many horrendous and pinching effects knock such as premature deaths especially in many countries of the developing world hardest hit by it. This has for example burgeoned the statistics for the orphans and vulnerable children that need to be taken care of by societies and governments. The situation is especially grave in South Africa, the country with the highest number of people living with HIVIAIDS in the world. The country has more than a million are orphaned by HIVIAIDS (Ramphele 2008; Statistics South Africa 2010).

Moreover, Sub-Sahara Africa remains one of the most affected regions with $4.9 \%$ of the adults living with HIV and accounting for $69 \%$ of the people living with the virus globally (http://www.who.int 2013). South Africa is home to about 5.6 million people living with HIVIAIDS (UNAIDS as cited by http://www.aids.org.za 2013). There are various ways that determine HIVIAIDS epidemiology. Gender factors include the low status of women, inequality, uneven access to medical care as well as poor management and administration to respond to the epidemic (http://www.aids.org.za 2013). In relation to the treatment of those living with HIVIAIDS, many obstacles have been faced associated with the government's fear that the cost of the administration of ARVs to the needy would soon be unaffordable. The political goodwill to manage and face the epidemic is also an issue that needs to be factored in when considering the chances of success in combating HIVIAIDS. It is this scenario of divided government goodwill to face the disease head on that prompted NGOls such as the Treatment Action Campaign (TAC) to promulgate significant resistance and research based advocacy to prove the importance of the ARV treatment programme and how it needs to be made affordable (http://www.internationalbudget.org 2011); TAC 2007).

When the South African government finally acknowledged the need for administering the ARVs to all who needed it and therefore registered its commitment to roll out the plan, the programme began to be rolled out to as many people as possible (http://www.internationalbudget.org 2011). This programme of endeavouring to roll out the ARVS and manage the disease is known as NIMART. Its aim is to increase the access to treatment and also as a cost effective programme. The programme's inception was also informed and driven by the acknowledgement that $80 \%$ deaths from PLWHA occurred to those who were diagnosed in their first year and yet were not accessed with the ART (Cameron et al 2012). However, although the programme started out well, the implementation was surrounded by problems especially where the NGOs were collaborating with the government. Expectedly, the government was to fund all the operations of the rolling out while bodies such as the NGOs implement the blue print. This was under the government/NGO pact. Apparently, it appears that the government has not adequately been discharging its task of funding to ensure medication and all the other dispensing infrastructure is in place. It is therefore important to explore the terrain of the collaboration with the aim of coming up with recommendations that can expedite the process of rolling out the ART programme. These gaps such as inadequate human resource to dispense medication, and lack of medication itself could have serious spinoffs such as making the PLWHA experience default. This could make them move from one line of the disease to the next one and therefore make them move to their graves fast (TAC 2007). Medication could be there, but inadequate staff especially the qualified one to administer and dispense it is critical. It could easily lead to the programme collapse or inadequate result -oriented. It is therefore timely and critical for a study that will explore the panacea of the collaboration between the government and NGOs in service delivery. In this paper, these researchers are exploring the Nurse Initiated in the Management of Anti-Retroviral Therapy (NIMART) programme run by IYDSA and the government of South Africa with the ultimate goal of training the nurses in primary health care facilities so that they can be able to initiate treatment on their own (http://www.iydsa.coza 2013). 


\section{Methodology}

\subsection{Study Design and Paradigm}

The study adopted a qualitative research paradigm because the study sought to explore the perception of the beneficiaries (nurses of IYDSA) on the panacea of the collaboration between the government and NGOs in service delivery. The qualitative research paradigm was especially important to collect the feelings, views and experiences of the study participants in order to establish their thinking on the subject matter (Rubin \& Babbie 2011). The study design took the form of a case study. The study was exploratory and descriptive in nature as this area has not been extensively investigated.

\subsection{Methods of Data Collection}

The qualitative data collection entailed the use of one-on-one in-depth interviews as well as focus group discussion administered by one of the researcher. Focus group discussion method was especially important because it was inexpensive and not time consuming, and the dynamics that emerged from the focus group discussion enabled collection of data even from issues that the researchers had not thought of (Rubin \& Babbie 2011). Moreover, in-depth interviews were also chosen because they enabled the researchers to collect rich data and to understand more about the problem (Stacks 2010).

\subsection{Sample Selection}

This study utilized non-probability sampling methodology which took the form of purposive and snow ball sampling techniques. The researcher utilized purposive sampling in selecting the monitoring and evaluation manager and then snow ball sampling was used to select the Pharmacist and the 9 nurses from IYDSA. Purposive sampling was especially important because it enabled the researcher to select the samples that carried the desired research attributes (Neuman 2006); and snow ball sampling enabled the researcher to get information about the other samples unknown to researcher or uneasy to locate (Babbie 2011).

\subsection{Research Instruments}

The study adopted an interview guide as a data collection tool with semi structured questions to guide the focus group discussions with the 9 IYDSA nurses and one-on-one in-depth interviews with the two IYDSA programme staff. The latter two served as key informants for the study.

\subsection{Units of Analysis}

Nine (9) nurses from IYDSA responsible with training nurses from primary health care facilities were subjected to a focus group discussion; while one Monitoring and Evaluation Manager and a Pharmacist for IYDSA were subjected to one-onone in-depth interview. The 9 nurses were interviewed from their head office (IYDSA) in Vincent, East London, while the Pharmacist and IYDSA Monitoring and Evaluation manager were interviewed from their offices at the head office (IYDSA) in East London respectively. The latter two acted as key informants because they were more knowledgeable about the programme.

\subsection{Data Collection and Analysis}

This researcher utilized an audio tape recorder to collect data from the focus group discussions and interviews with the participants. The audio taped data was transcribed later on after the interview, while notes were also taken to complement the recorded data. The qualitative data was then analysed using the content thematic analysis whereby raw data was ordered, categorized and rearranged into themes according to the emerging views of the participants.

\subsection{Research Domain}

The data was collected in November 2012 in Vincent, East London at the head office of IYDSA. The place was 
essentially chosen because it was easier to get the nurses at one point when they are in their headquartered office than to follow them in their primary health care facilities where it would have been difficult to get them together in one place, usually because of transport logistics. The monitoring and evaluation manager and the pharmacist were especially important because they were knowledgeable about the NIMART programme, while the nurses were the ones who had hands- on- experience in ARV administration and dispensing of medication since they were training the nurses in primary health facilities.

\section{Findings}

\subsection{Profile}

\subsubsection{Gender}

The findings indicated that there were 8 females and 1 male from the nurses that were subjected to a focus group discussion. These findings indicate that more females were taking the post of nurses than males which could be due to subjective cultural perspectives that indicate that nursing is a feminine field than the masculine domain. It could therefore be a positive contribution if the government and NGOs can put in place affirmative action programmes to encourage the males to opt for nursing as a way of strengthening the domain. As long as the traditional gender norms of role and professional differentiation and segregation based on gender are not dismantled especially in the developing part of the world where gender largely affects development and empowerment of women, it would be difficult for these countries to make a significant score in their countries Millennium Development Goal number three that envisage to achieve gender equality and equity and women economic and social empowerment. This calls for the governments and communities to work towards diluting cultures, especially the patriarchal ones that strongly see women as subordinate to their male counterparts (Kang'ethe 2009, 2010). Having men on board to take nursing could be a blessing to address the challenges of understaffing in government hospitals as well as unemployment in South Africa.

\subsubsection{Shortage of human resources}

The findings from this study revealed that there were challenges of inadequate human resource such as pharmacists and nurses in primary health care centres of Eastern Cape Province. These findings were supported by the following sentiments from the beneficiaries and key informants subjected to an in-depth interview:

"Regarding staff, currently there is roughly about $35-40 \%$ shortage of pharmacy staff in the Eastern Cape only and $40 \%$ staff shortage of assistants pharmacists. Ideally, every facility is supposed to have one qualified assistant pharmacist. Out of 59 health centres, only 2 of them have pharmacy staff. The nurses are also a few at the primary health care centers and sometimes we find no one to train".

These findings revealed a serious shortage of human resources in primary health care facilities such as pharmacists and nurses. It is against this backdrop that these researchers think the government is not taking the issue of capacitating health centres with adequate human resources seriously for the effective implementation of NIMART. Sometimes nurses from IYDSA go to these primary health care centres to train the nurses, but sometimes the nurses are overloaded with work to an extent that they cannot avail themselves for training. This impedes the progress of the NIMART programme because training is likely to be inconsistent, or does not take place at all. With the commitment of NGOs, it would be ideal for the government to consider strengthening its commitment to ensure that the NIMART programme is given support in order to carry its tasks expeditiously.

\subsubsection{Maladministration of medical facilities by the government}

The findings from this study revealed that there were some maladministration issues such as not failing to ensure timely procurement of medication in the primary health care facilities. Sometimes there were no stocks at all. These findings were supported by the following sentiments from the beneficiaries and key informants who were subjected to an in-depth interview:

"These primary health care facilities have problems because they are usually out of stock and it shows the government does not keep record of what is needed and they end up depending on IYDSA for everything". 
These findings revealed that the government hospitals were rocked with maladministration as they medication stock flow was erratic and inconsistent. This prompted these centres to end up placing unnecessary burden on IYDSA for various resources. These researchers think this kind of administrative flaws/gaps is letting the NGO fraternity down and jeopardizes the spirit and practice of government-NGO collaboration in the fight against HIVIAIDS. This indicates the need for the South African Health Ministry concerned with HIVIAIDS campaign and ensuring a well stocked medical resources to put in place proper planning and monitoring tools that will ensure that all required resources are budgeted for and allocated to these primary health care centres. Timely procurement and stock taking are critical if the campaign is to run smoothly and effectively. This is because the failure to properly administer these centres may derail the performance of the country towards ensuring accessibility to health to all its citizens. This should concern the South African AIDS Council so that advocacy to remedy is situation is intensified (South African National AIDS Council 2008).

\subsubsection{Poor roads and long distances leading to fatigue}

The findings from this study revealed that the roads leading to the primary health care centres were poor and the long distances were promoting fatigue on the nurses from IYDSA. This made their productivity to drop as well as slackened their motivation to work. These findings were supported by the following sentiments from the beneficiaries who were subjected to an in-depth interview:

"It is very painful and tiring to go to these hospitals and clinics because they are located very far. The roads are so bad and we are so much fatigued with the travelling".

These findings revealed that most of the nurses were stressed and not happy with the long distances they had to travel to the primary healthcare facilities. This means that their work environment was not conducive. This is because of the geographical locale of the clinics and hospitals they had to visit to carry out training. Apparently, the experience could make them develop psychological stress that would affect their productivity. Since the health and psychological well being of these people is of paramount concern, it is necessary that the government ministries such as road works consider working towards constructing durable and qualitative roads leading to these primary health care centres. This could be easily facilitated through the Expanded Public Works Programme which could also provide employment to those residing in the location of the centres. Importantly, the government could consider accommodating these nurses close to or in the location of these hospitals

\subsubsection{Inadequate health infrastructure in the Primary Health Care centres}

The findings from this study revealed that there was shortage of infrastructure on the government facilities. These findings were supported by the following qualitative sentiments from the beneficiaries who were subjected to an in-depth interview.

"The Department of Health is really letting down these clinics and hospitals until IYDSA has to provide some of the equipment such as air conditioners, BP machines, screening machines, and burglar gates".

These findings from this study revealed that the government is failing to adequately consider capacitating the health centres with requisite infrastructure, whether physical social or otherwise. This definitely makes the operations of the NGOs difficult and an arduous task. It is based upon these findings that these researchers recommend the government to consider seriously providing adequate infrastructure to make it easy for these health care facilities to provide treatment to the PLWHA.

\section{Discussion of the Findings}

The findings indicated that there were more female nurses than the males. This indicated a state of gender discrepancy as females were more than males. It is however not shocking because South Africa is a country where the females generally outnumber the males (Statistics South Africa SSA 2010). However, this is not just a demographic issue, but also a gender one where the tasks of nursing have traditionally been viewed to be a task of females and not of males. With the preponderance of HIVIAIDS in South Africa (Barnett \& Whiteside 2006; Ramphele 2008), this state of gender role differentiation, segregation and determination of roles need to be tackled. A lot of advocacy and lobbying by government and campaign architects and community leaders need to offer leadership and urge the communities to 
undergo a paradigm shift where the nursing tasks can be taken by any gender. This may not be as easy as it is said. A lot of work needs to be made on diluting the patriarchal thinking that have made strong bonds of these role differentiation (Kang'ethe 2009, 2010, 2011; Gender Link 2012).

Findings also indicated immense shortage of nurses in the care centres. This is a phenomenon affecting many countries of the developing world (WHO 2002). First, there are inadequate resources to train as many nurses as possible. This is especially acute in the domain of HIVIAIDS which is still regarded as a new disease (Nurses Association of Botswana (NAB) 2004; Uys and Cameron 2003; UNAIDS 2001). Second, many nurses have left the country to take overseas jobs. On the ground, the nursing profession seems to face many challenges such as inadequate salaries, limited career opportunities, poor nursing leadership, poor public image and huge workload as a result of insufficient staff, poor working conditions and lack of safety and security in the workplace (Oosthuizen \& Ehlers 2007; Brier 2009). Perhaps also the fact that many foreign nationals encounter problems in registering with the South African council of Nursing could also pose the challenge of inadequate number of nurses in the country (South African Nursing Council (SANAC) 2008). Other perceptions also indicate the need for societies to undergo a paradigm shift in their mindset, ideologies and thinking to consider gender rearrangements, gender swap and attitudes that all the tasks of humankind should be gender neutral. This will offload some of the professions that suffer immense gender preponderance such as nursing and care giving (Kang'ethe 2009, 2010, 2011). The government of South Africa could take lessons from Botswana's Vision 2016 of working towards achieving a state of gender neutrality and sensitivity in care giving towards addressing the HIV epidemic (Government of Botswana 1997).

The findings from this study established that there were challenges surrounding the implementation of NIMART in government hospitals such as inadequate or shortage of infrastructure around primary health care centres, poor roads and long distances leading to fatigue of the trainers and shortage of human resources as well as poor administration of medical facilities by the government. This being a characteristic of most health domain in countries of the developing part of the world, the state posed serious drawback to the effectiveness and implementation of the programme (WHO 2002). The state made the training process to be a lagged out process, taking too long to achieve its programmed objectives (UNAIDS 2001).

Other perceptions also revealed that the NIMART programme was also facing challenges regarding the huge paperwork from the health work (Georgeu et al 2012). This was due to inadequate staffing. There is therefore a serious need for the government to provide more nurses to work overload, fatigue and possible burnout (NAB 2004; Uys \& Cameron 2003). The government needs to improve the working conditions to avoid the nurses leaving to western world where they are paid handsomely (Oosthuizen \& Ehlers 2007; Brier 2009). To further confirm this point other findings also indicated that the fact of overworking the nurses due to being fewer in number was affecting their motivation to work and possibly their output (Cameron et al 2012) It is therefore important that workers working environment is made conducive. The government needs to understand that there is an inextricable relationship between good and conducive working conditions and productivity (Lawler 1994).

The scenario above is also supported by perceptions that indicate that health care facilities in South Africa are experiencing a shortage of nurses and this could negatively be affecting the performance of these institutions (DENOSA 24 October 2007 as cited by Wildschut \& Mqolozana 2008). This is disturbing given that before the national ARV rolls out in 2002, many people who needed ARVs but could not access them succumbed to death (TAC 2007).

Findings also indicated that both physical and social infrastructure impeded the success of the programme's effectiveness. Transport was posing a serious challenge making it difficult for for medication to be moved from the procurement stations to the centres. This was acute in Amathole District. This is an issue that calls for the government to consider renovating and upgrading the road system especially in rural areas (Dana et al 2012). This could also motivate the efforts by NGOs who would want to partner with the government in service delivery. The centres' communication was also hindered by having some telephones not working (Georgeu et al 2012). Literature also indicates that infrastructural shortages largely impeded the effectiveness of the programme because of lack of operational space in the health centres. From a study that sampled nurses from the 7 provinces of South Africa, they reported that their work was impeded because they did not have a room where they could consult the patients (Cameron et al 2012). This is further supported by other findings that indicate that infrastructural challenges such as consulting rooms were also impeding the success of the NIMART programme (Nyasulu et al 2013). This points out to a serious weakness by the government for failing to improve both the physical and social infrastructure around the health centres. This is further confirmed but sentiments that indicated that there were shortages of stationery and registering files (Cameron et al 2012). The shortage of these vital resources is a hindrance to any monitoring and evaluation tools to measure the impact of such programmes. This poses serious government-NGO pact and ultimately the efforts to respond to HIVIAIDS in South Africa. Perhaps this poor government-NGO pact could form reasons why strategies to respond to HIVIAIDS in South Africa are moving at a snail's 
pace.

\section{Recommendations}

In light of the above findings, these researchers have proposed the following recommendations as a way to strengthen the collaboration between NGOs and government in service delivery especially with regards to the NIMART HIVIAIDS programme:

- The government through its ministry of roads needs to engage in reconstruction and renovation of the roads to ensure that it is easier for NGOs and any other stakeholders to reach the primary health care facilities

- The construction of enough infrastructure and purchase of essential clinical equipment cannot be overemphasized if the government is to seriously bolster the problems of infrastructure and maladministration.

- The national marketing and promotion of the nursing qualification is long overdue to attract human resources as well as in pharmaceutical and data capturing areas. Funding those programmes for learners that select them could also go a long way in marketing the programme. Having the government and leaders of various cadres advocate and lure the communities to adopt a gender neutral attitude could also raise the interest of the males to consider taking nursing profession to assist the female counterparts.

\section{Conclusion}

It is commendable that South Africa has managed to stage meaningful intervention to address challenges imposed by the HIVIAIDS epidemic especially through the implementation og the NIMART (Nurse Initiated in the Management of AntiRetroviral Therapy) programme. Despite the statistics indicating an increase in the number of people receiving treatment, many problems surround the state of collaboration between the government and the NGOs especially those pursuing the training of nurses at primary health care facilities. Such challenges includes poor physical and social infrastructure, lack of requisite medication, erratic stocking of it, and inadequate human resource to implement the HIVIAIDS programmes in the primary health care facilities among other things. It is pertinent therefore for the government to take these recommendations into consideration and improve these challenges so that the country can take advantage of the NGOs in the field of HIVIAIDS to expeditiously respond to the disease. The NGOS needs government goodwill and a palatable and conducive atmosphere that can be created by the government. Such a pact can be a panacea and can no doubt pay great dividends through turning around the lives of people living with HIVIAIDS.

\section{References}

Babbie E 2011. The basics of Social Research. Cengage Learning Barnett T \& Whiteside A 2002. AIDS in the Twenty-First Century. Disease and Globalization. Hampshire: Palgrave Macmillan.

Brier M 2009. Doctors. In: Erasmus J, Brier M, eds. Skills Shortage in South Africa: Case Studies of Key Professions. Cape Town: HSRC Press, 2009.

Cameron D, Gorber A, Mbatha M, Mutyabele J, Swart H 2012. Nurse initiation and maintenance of patients on antiretroviral therapy: Are nurses in primary care clinics initiating ART after attending NIMART training? South African Medical Journal, 102 (2).

Dana P, Ewing RG \& Gogela KB 2012. An assessment of the antiretroviral therapy programme in health facilities in the Amathole and Alfred Nzo Districts of the Eastern Cape Province. ECAC:

Gender links. 2012. The gender based violence indicators study Botswana. http://www.genderlinks.org.za/article/the-gender-basedviolence-indicators-study- botswana-2012-03-28

Georgeu D, Colvin C J, Lewin S, Fairall L, Bachmann M O, Uebel K, Zwarenstein M, Draper B, \& Bateman E D 2012. Implementing nurse-initiated and managed antiretroviral treatment (NIMART) in South Africa: a qualitative process evaluation of the STRETCH trial. Bio Med Center. The Open Access Publisher.

Government of Botswana 1997. Vision 2016. Towards Prosperity for all. Presidential Task group for a long term vision for Batswana, September 1997.

htttp://www.aids.org.za 2013. HIVIAIDS in South Africa. Retrieved on 09/10/2013

http://www.who.int 2013. Global health observatory (GHO). Retrieved on 09/10/2013

http://www.internationalbudget.org 2011. In the Face of Crisis: The Treatment Action Campaign Fights Government Inertia with Budget Advocacy and Litigation. Retrieved on 09/10/2013.

http://www.iydsa.coza 2013. NIMART. Retrieved on 09/10/2013

Kang'ethe SM 2009 ."Inadequate Male involvement in Health Issues: The cause of gender skewed HIV and AIDs situations in Botswana". In Maundeni, T, Osei-Hwedie, B.Z.,

Mukaamambo, E. \& Ntseane, P.G. (eds). Male Involvement in Sexual and Reproductive Health. Prevention of Violence and HIV/AIDS in 
Botswana. Made Plain Communications, Cape town.

Kang'ethe SM 2010. The perfidious experiences of men as palliative caregivers of people living with HIVIAIDS and other terminal illnesses in Botswana. Indian Journal of Palliative Care. Sep-Dec 2010/Vol-16/Issue-3. Pp 159-164.

Kang'ethe S M 2011. Gender discrepancies abound in Community Home Based Care Programme (CHBC) in Botswana. S. Afr. Fam. Pract. 2011.7. Vol 53. No 5. Pg. 467-473.

Lawler E E 1994. Motivation in work organizations: San Francisco: Jossey-Bass

Neuman W L 2006. Social research methods: qualitative and quantitative approaches: Pearson/Allyn and Bacon.

Nurses Association of Botswana (NAB) 2004. Caring for the Caregivers. Gaborone, Kgotla Designs PTY LTD, Botswana.

Nyasulu J C Y, Muchiri E, Mazwi S, Ratshefela M 2013. NIMART rollout to antiretrovirals in Johannesburg: An interrupted time series analysis. South African Medical Journal, 103 (4): 232-236

Oosthuizen M, Ehlers VJ 2007. Factors that may influence South African nurses' decision to emigrate. Health SA Gesondheid 2007;12(12):14-26.

Ramphele M 2008. Laying Ghosts to Rest. Dilemmas of the Transformation in South Africa. Cape Town: Tafelberg.

Rubin A \& Babbie E 2011. Research Methods for Social Work. Cengage Learning

South African Nursing Council (SANC) 2008. South African Nursing Council statistics. 2008. http://www.sanc.co.za/stats/ (accessed 3 June 2011).

Stacks D W 2010. Primer of Public Relations Research. Second Edition. Guildford Press.

Statistics South Africa (SSA) 2010. Mid-year population estimates 2010. Pretoria: Statistics South Africa. Available at http://www.stats.gov.za/publications/p302/p3022010.pdf. Retrieved on 23/01/2013

TAC (Treatment Action Campaign) 2007. 'Government Leadership on HIVIAIDS Irerevocably Defeats Denialism!Implement a New Credible Plan with Clear Targets!'Available at http://www.tac.org.za/AIDSDEnialismlsDead.html. (Accessed on 22nd February 2007).

UNAIDS 2001. Promoting excellence in training. The Regional Training Network (RATN). UNAIDS Best Practice Collection. June. Geneva, Switzerland.

Uys L and Cameron S 2003. Home Based HIVIAIDS Care. Capetown. Oxford University Press.

Wildschut A \& Mqolozana T 2008. Shortage of nurses in South Africa: Relative or Absolute? Case study report, forming part of the HSRC study: A multiple source identification and verification of scarce and critical skills in the South African Labour Market. Commissioned by the Department of Labour. South Africa .

WHO 2002. Community Home -Based Care in Resource- Limited Settings. A Framework for Action. 20 Avenue Appia, 1221 Geneva 27, Switzerland; 2002. 